\title{
Epigenetic mechanisms and the relationship to childhood asthma
}

\author{
M. Kabesch*, S. Michel*,* and J. Tost ${ }^{\#}$
}

\begin{abstract}
Epigenetic mechanisms mediate genomic adaption to the environment and epigenetic alterations can contribute to the development of disease phenotypes, as can genetic variants. A variety of molecular mechanisms are involved in epigenetic regulation, including posttranscriptional histone modifications, histone variants, ATP-dependent chromatin remodelling complexes, polycomb/trithorax protein complexes, small and other noncoding RNAs (small interfering RNA and micro RNAs) and DNA methylation. Epigenetic mechanisms have been identified in cancer but very little is known about these effects in complex diseases such as asthma. Epigenetic mechanisms have been found to play a primordial role in T-cell differentiation and novel aspects of asthma and allergy development are now investigated by systematic epigenetic studies. Here we give an introduction to epigenetics, review the existing literature in relation to asthma and asthma-related mechanisms and hypothesise on feasible approaches for the study of epigenetics in asthma in the future.
\end{abstract}

\section{KEYWORDS: Asthma genetics, epigenetics}

E pigenetics can be defined as the study of heritable changes of a phenotype, such as the gene expression patterns of a specific cell type that are not caused by changes in the nucleotide sequence of the genetic code itself. Epigenetic mechanisms convey genomic adaption to an environment, thereby ultimately contributing towards the phenotype. Epigenetic phenomena are mediated by a variety of molecular mechanisms, including post-transcriptional histone modifications, histone variants, ATP-dependent chromatin remodelling complexes, polycomb/trithorax protein complexes, small and other noncoding RNAs (including small interfering RNA and micro RNAs (miRNAs)), and DNA methylation [1]. Chromatin modulations play a central role in shaping the epigenome and delineate a functional chromatin topology which serves as the platform forming regulatory circuits in all cells. Open (euchromatin) and closed (heterochromatin) chromatin states are controlled by histone modifications and histone composition in close crosstalk with the binding of a myriad of non-histone proteins (fig. 1). The basic building block of chromatin is the nucleosome, which is formed of an octamer of histone proteins containing an $\mathrm{H} 3-\mathrm{H} 4$ tetramer flanked on either side with an H2A-H2B dimer around which 146 base pairs of DNA are spooled. The protruding N-terminal tails of these histones undergo extensive changes caused by various modifications such as acetylation, methylation, phosphorylation and ubiquitylation [2]. The combination of different $\mathrm{N}$-terminal modifications and the incorporation of different histone variants that have distinct roles in gene regulation have led to the proposition of a regulatory histone code, which determines, at least partly, the transcriptional potential for a specific gene or a genomic region [3]. These diverse molecular mechanisms have all been found to be closely intertwined and stabilise each other to ensure the faithful propagation of an epigenetic state over time and, in particular, through cell division. Nonetheless, epigenetic states are not definitive and changes occur over time in a stochastic manner as well as in response to environmental stimuli.

Previous articles in this series: No. 1: Hedlin G, Bush A, Lødrup Carlsen K, et al. Problematic severe asthma in children, not one problem but many: a GA²LEN initiative. Eur Respir J 2010; 36: 196-201. No. 2: Xepapadaki P. Papadopoulos NG. Childhood asthma and infection: virus-induced exacerbations as determinants and modifiers. Eur Respir J 2010; 36: 438-445. No. 3: de Groot EP, Duiverman EJ, Brand PLP. Comorbidities of asthma during childhood: possibly important, yet poorly studied. Eur Respir J 2010; 36: 671-678.

European Respiratory Journal Print ISSN 0903-1936 Online ISSN 1399-3003

\section{AFFILIATIONS}

${ }^{*}$ Centre for Paediatrics, Clinic for Paediatric Pneumology and Neonatology, Hannover Medical School, Hannover, Germany.

\#Laboratory for Epigenetics, Centre National de Génotypage, Institut de Génomique, Commissariat à l'Énergie Atomique, Evry, France.

\section{CORRESPONDENCE}

M. Kabesch

Centre for Paediatrics

Clinic for Paediatric Pneumology,

Allergology and Neonatology

Hannover Medical School

Carl-Neuberg-Str. 1

D-30625

Hannover

Germany

E-mail: kabesch.michael@mh-

hannover.de

Received:

Feb 042010

Accepted after revision:

April 202010 
Epigenetic modifications contribute to so many processes that, for the purposes of this review, oversimplifications and large omissions are unavoidable. In this manuscript, we will mainly concentrate on DNA methylation, the best studied form of epigenetic modification and, very briefly, touch on regulation through miRNA, an epigenetic mechanism acting on gene expression in a dynamic and tissue-specific manner.

\section{DNA METHYLATION}

DNA methylation is the only genetically programmed modification of DNA itself that is presently known in mammals. All other epigenetic effects act on proteins interacting with DNA or at the level of RNA interference. This post-replication modification is almost exclusively found on the 5 position of the pyrimidine ring of cytosines in the context of the dinucleotide sequence CpG (fig. 2) [4]. 5-Methylcytosine accounts for $\sim 1 \%$ of all bases and the majority (75\%) of $\mathrm{CpG}$ dinucleotides throughout mammalian genomes are methylated. Owing to their inherent mutagenicity, CpGs are underrepresented in the genome, but relatively CpG-rich clusters of approximately $1-4 \mathrm{~kb}$ in length, so-called $\mathrm{CpG}$ islands, are found in the promoter region and first exons of many genes. In contrast to single CpGs, they are mostly nonmethylated, corresponding to open chromatin structure and a potentially active state of transcription [5]. About three-quarters of transcription start sites and $88 \%$ of active promoters are associated with $\mathrm{CpG}$-rich sequences and might be regulated by DNA methylation.

This regulation is controlled in a tissue- and developmental stage-specific manner. Thus, mechanisms of epigenetic regulation and the degree of epigenetic modification vary between different cells and tissues (e.g. between lung epithelial cells and blood). Sufficient and balanced quantities of several dietingested molecules, such as folic acid, vitamin B12, choline, betaine and niacine, are important for the correct establishment and maintenance of epigenetic modifications throughout the genome. DNA methylation levels correlate with the levels of available folate and the genotype-dependent activity of enzymes involved in methylation, such as the 5,10-methylenetetrahydrofolate reductase gene [6]. So far, four DNA methyltransferases have been identified (DNMT1, DNMT3A, DNMT3B and DNMT2) as well as a DNMT-related protein (DNMT3L) [7, 8]. The first three catalyse the transfer of a methyl group from the universal methyl donor S-adenosyl-Lmethionine to the cytosine base in DNA. Put simply, DNMT1 acts as maintenance methyltransferase as it has a preference for hemi-methylated templates. It is located at the replication fork during the $S$ phase of the cell cycle and methylates the newly

\section{a) Euchromatin}

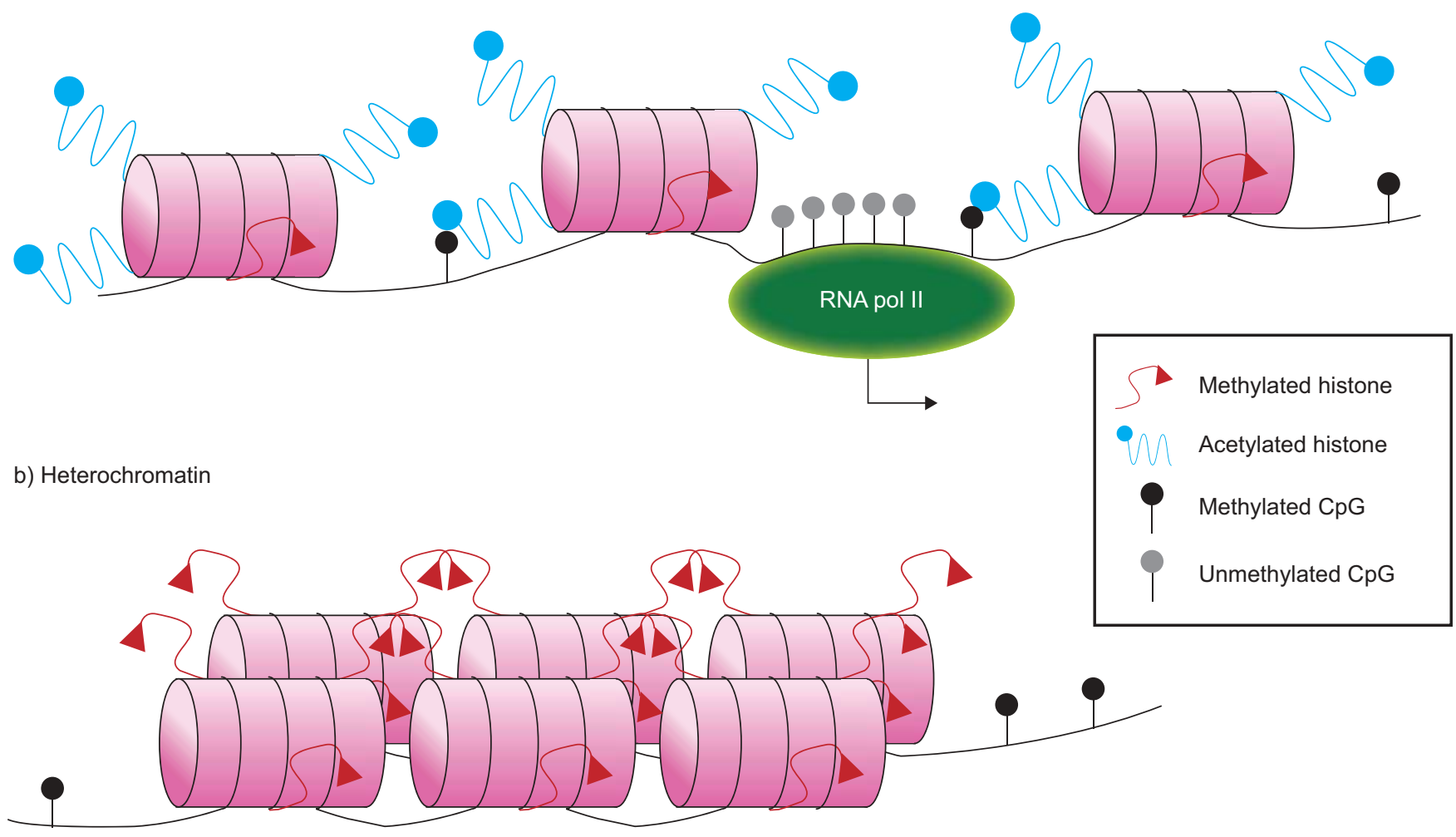

FIGURE 1. Schematic representation of euchromatin and heterochromatin. a) In euchromatin, the promoter CpG island (๑) is an accessible nucleosome-free region. RNA polymerase binding to transcription start is possible. Histone hyperacetylation including lysine 9 of histone $\mathrm{H} 3$ ( $\mathrm{H} 3 \mathrm{~K} 9$ ) is simultaneously present with the methylation on lysine 4 of $\mathrm{H} 3(\mathrm{H} 3 \mathrm{~K} 4)$. b) In heterochromatin, the nucleosome structure and, therefore, also the DNA is compacted and the region is transcriptionally silent. H3K4 is demethylated, whereas H3K9, H3K27 and H4K20 are methylated like DNA. For simplification, only selected histone modifications associated with the chromatin state are shown. 


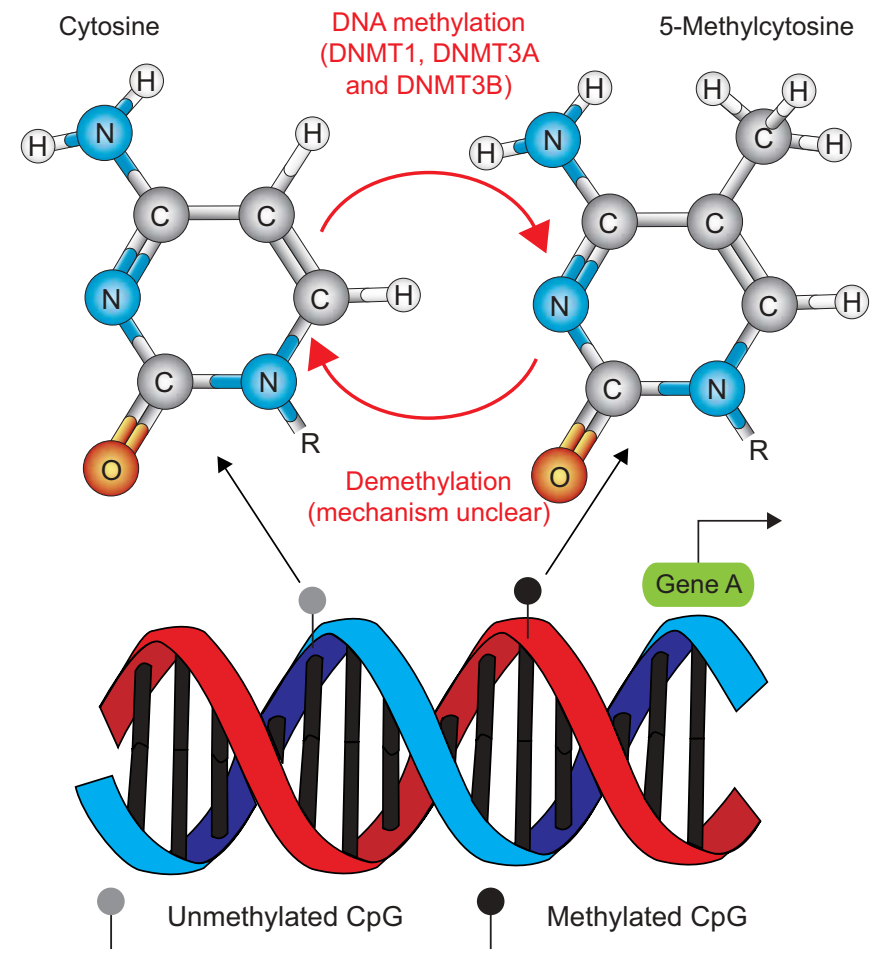

FIGURE 2. The principle of methylation and the chemical structure of cytosine and 5-methylcytosine. $\mathrm{R}$ is the connection to the DNA backbone.

synthesised DNA strand using the parent strand as a template. Consequently, it passes on epigenetic information over cell generations. De novo methylation is carried out by the methyltransferases DNMT3A and DNMT3B. These enzymes have a preference for specific targets but also work cooperatively to methylate the genome. Possible trigger mechanisms to initiate de novo methylation include preferred target DNA sequences, RNA interference, certain chromatin structures induced by histone modifications and other protein-protein interactions $[7,8]$.

Although active demethylation of DNA undoubtedly occurs during development, the exact mechanisms for global and gene-specific demethylation events are still unclear and subject to much debate; all postulated mechanisms are not very efficient, indicating that the underlying mechanisms might be more complex than currently understood $[9,10]$.

\section{Regulation of transcription by epigenetic modifications}

Transcription does not occur on naked DNA but in the context of chromatin, which critically influences the accessibility of the DNA to transcription factors and the DNA polymerase complexes. DNA methylation, histone modifications and chromatin remodelling are closely interwoven and constitute multiple layers of epigenetic modifications for the control and modulation of gene expression through chromatin structure [11]. DNMTs and histone deacetylases (HDACs) are found in the same multi-protein complexes and methyl-binding proteins interact with HDACs and histone methyltransferases, as well as with the chromatin remodelling complexes. In many cases DNA methylation follows changes in the chromatin structure and is used as the molecular mechanism to permanently and, thus, heritably lock the gene in its inactive state [4].

Cytosine methylation of $\mathrm{CpG}$ dinucleotides is found in close proximity to critically important cis-elements within promoters and is often associated with a repressed chromatin state and inhibition of transcription. In many cases, methylated and silenced genes can be reactivated using DNA methylation inhibitors such as 5-azacytidine. Methylation can interfere with transcription by inhibiting the binding of transcriptional activators with their cognate DNA recognition sequence such as Sp1 and Myc through steric hindrance. In addition, methylcytosine binding proteins (MBDs, MeCP2, UHRF, Kaiso and ZBTs) recruit transcriptional corepressors, such as histone deacetylating complexes, polycomb proteins and chromatin remodelling complexes, and attract chromodomain binding proteins to establish a repressive chromatin configuration [12].

\section{Relevance of DNA methylation}

Cytosine methylation is essential for mammalian embryogenesis, during which methylation levels change dynamically [13, 14]. Epigenetic modifications are of particular importance for imprinted genes, i.e. a subset of genes that is asymmetrically expressed from only the maternal or the paternal allele in a parent-of-origin-specific manner in all somatic cells of the offspring [15]. These imprinted genes are generally located in clusters and the alleles are differentially marked by DNA methylation, histone acetylation/deacetylation and histone methylation and often associated with antisense RNAs [16, 17]. Imprinted genes are probably the most important buffering factors for regulating the day-to-day flux between mother and fetus in placental mammals. DNA methylation plays an important role in the maintenance of genome integrity by transcriptional silencing of repetitive DNA sequences and endogenous transposons [18]. Random silencing of one of the two $\mathrm{X}$ chromosomes in embryonic tissues of female mammals to achieve dosage compensation is another paradigm for a stable and heritable epigenetic state in somatic cells [19].

Epigenetics holds promise for the explanation of at least a part of the influences the environment has on a phenotype. Studies in monozygotic twins demonstrated that epigenetic differences in such genetically identical humans accumulate with age and different environments create different patterns of epigenetic modifications [20]. Differences are, therefore, largest in twin pairs of old age that have been raised separately. Transient nutritional or chemical stimuli occurring at specific ontogenic stages may have long-lasting influences on gene expression by interacting with epigenetic mechanisms and altering chromatin compaction and transcription factor accessibility. In particular, modifications to the environment during early development can lead to permanent changes in the patterns of epigenetic modifications. Epigenetics might, therefore, provide a mechanism by which physiological homeostasis could be developmentally programmed and inherited.

\section{EPIGENETICS AND DISEASE}

DNA methylation and chromatin structure have been found to be strikingly altered in many pathological situations, particularly cancer and various mental retardation syndromes. Altered levels of folate and homocysteine have been repeatedly 
linked to disease. Even so called monogenetic diseases, such as $\alpha$-thalassaemia, that have previously been attributed solely to genetic alterations, can be caused by epigenetic alterations at the same locus [21].

Cancer is probably the most extensively studied disease with a strong epigenetic component [22]. In tumours a global loss of DNA methylation (hypomethylation) of the genome is observed. The overall decrease in DNA methylation is accompanied by a region- and gene-specific increase of methylation (hypermethylation) of multiple CpG islands, often associated with transcriptional silencing of the associated gene. Genes of numerous pathways involved in signal transduction, DNA repair, detoxification, cell cycle regulation, differentiation, angiogenesis and apoptosis are often inappropriately inactivated by DNA methylation. Methylation analysis can be carried out in cancer tissue itself but, more importantly, recent reports have demonstrated a high level of concordance of DNA methylation patterns in tumour biopsies and matched DNA samples extracted from body fluids such as serum, plasma, urine and sputum [23, 24]. As DNA methylation is a non-mutational and, therefore, at least in principle, a reversible modification, it can be used as point of departure for anti-neoplastic treatment by chemically or antisense oligonucleotide-induced demethylation [25].

\section{DNA METHYLATION AND COMPLEX DISEASE}

While most interest has been focused on epigenetic mechanisms in cancer, it is very likely that epigenetic changes also contribute directly or indirectly to the development of many complex and multifactorial diseases. Genetic variations so far identified to confer susceptibility to complex diseases only explain a small fraction of the disease risk. Epigenetic mechanisms are capable of explaining various non-Mendelian features of multifactorial diseases, such as the relatively high degree of discordance in monozygotic twins. Undoubtedly, environmental factors also play a critical role in triggering the onset of complex diseases and epigenetic modifications constitute a memory of the stimuli or insults an organism has been exposed to. However, only a few of these complex diseases have so far been studied in detail with regard to their epigenetic component [26].

Epigenetic modifications might mediate adaptation of the organism to its environment, starting early in life [27]. Nutritional stress during early development seems to trigger systemic epigenetic modifications in mammals, especially of the metabolic gene network [28]. The modulation of epigenetic patterns in utero has given rise to the hypothesis that the in utero environment can cause permanent changes to metabolic processes, directly affecting postnatal phenotype and conferring susceptibility to multifactorial disease later in life [29, 30]. There is also evidence for transgenerational inheritance of epigenetic patterns leading to complex diseases, as a similar effect was observed in individuals thriving in affluent conditions but whose parents or even grandparents were nutritionally deprived [31].

\section{EPIGENETICS AND INFLAMMATORY/IMMUNE DISORDERS}

Epigenetic changes are also found in chronic inflammatory diseases in which epigenetic changes induced by inflammation contribute to the pathogenesis of the disease; for example, atherosclerosis is characterised by an increased degree of hypomethylation in vascular tissue and blood cells correlating with the severity of the disease [32]. Local DNA methylation alterations (hyper- and hypomethylation) have been found to precede aortic lesions in human cell line and mouse models, and might thus present a first stage of pathogenesis [33]. DNA hypomethylation is also observed in synovial fibroblasts [34] and in T-cells [35] from patients with rheumatoid arthritis. Autoimmune diseases, such as systemic lupus erythematosus, including drug-induced lupus, are characterised by hypomethylation of certain T-cell populations but without concomitant genomic instability [36, 37].

\section{EPIGENETICS, ASTHMA AND ALLERGY}

The investigation of epigenetic changes involved in the pathogenesis of asthma and allergy is still at a very early stage. Epigenetics may explain how genetic susceptibility and exposure to environmental factors interact in defining atopic disease phenotypes. Methylation is the most extensively studied epigenetic mechanism in asthma- and allergy-related genes and environmental effects. Apart from methylation, altered histone modifications might also play a role in asthma. There is evidence for an increased activity of histone acetyltransferases (HATs) and a simultaneous reduction of HDAC activity in asthmatic patients $[38,39]$. Both of these histone modification mechanisms can lead to hyperacetylation of the N-terminal histone tails, opening up chromatin structure and increasing gene transcription by facilitating the binding of transcription factors [40]. These modifications might potentially contribute to the increased expression of genes involved in inflammatory responses characteristic for asthma. Interestingly, hyperacetylation mechanisms were suppressed or even reversed when the asthmatics were regularly treated with inhaled steroids in some of those studies [39]. These effects are not only observed in asthma but have also been well defined in chronic obstructive pulmonary disease (COPD). There, total HDAC activity was found to be related to the severity of the disease [41]. One of the most prominent aspects in the development of asthma and allergy, in which epigenetic mechanisms are known to play an important role, is T-cell differentiation and regulation [42, 43], a crucial event in the onset of atopic disease.

\section{EPIGENETICS OF T-CELL DIFFERENTIATION, A HALLMARK OF ALLERGY}

The development of a naïve T-cell into a T-helper type 1 (Th1) or 2 (Th2) cell is associated with lineage-specific changes in epigenetic patterns. During differentiation towards Th1 cells, de novo methylation of the intergenic region between interleukin (IL) 4 and IL13 on chromosome 5q21 is observed [44], while histone acetylation remains at a low level comparable to that of naïve T-cells [45]. Both effects lead to a reduced activity of Th2-specific genes in Th1 cells. Additionally, the binding of T-bet to the promoter of interferon gamma (IFNG) not only induces promoter activity itself but dislocates HDAC-containing complexes, which in turn enables HATs to bind [46]. Likewise, the activity of the Th1-specific transcription factor (IFNG) is suppressed in Th2 cells by increased methylation of the IFNG gene locus, preventing nuclear factor of activated Tcells binding to the IFNG promoter [47]. In contrast, the IL13/ IL4 region undergoes extensive demethylation in Th2 lineage differentiation, which facilitates binding of the Th2-associated 
transcription factors STAT6 and GATA3 to the locus increasing expression levels of the respective genes [44]. Simultaneously with the demethylation of the DNA, histones in the IL13/IL4 region become acetylated [45] and the higher-order chromatin structure of the locus changes (figs 3 and 4) [48].

Regulatory T-cell (Treg) development and function is predominantly mediated by FOXP3, a member of the forkhead/wingedhelix family of transcription factors. Several studies have shown that at least in mice FOXP3 is influenced by various epigenetic mechanisms. An enhancer upstream of FOXP3 is methylated in naïve CD4+CD25- T-cells, activated CD4+ T-cells and transforming growth factor $\beta$-induced adaptive Tregs, but completely demethylated in natural Tregs [49]. Furthermore, the demethylation of an evolutionary conserved noncoding region upstream of exon 1 is necessary for stable FOXP3 expression [50]. As HDAC inhibitors enhance FOXP3 expression, it was also suggested that the level of histone acetylation of the FOXP3 locus plays a role in Treg development [51]. Histone acetylation may be involved in T-cell differentiation into Th17 cells as well. In Th1 and Th2 cells, the promoter regions of IL17 and IL17F were hypoacetylated, favouring the absent expression of these genes. However, in Th17 cells producing considerable amounts of IL17 and IL17F, increased histone acetylation has been detected [52].

Epigenetic mechanisms may also play a role in the regulation of cell-specific gene expression patterns of allergy-associated cytokines beyond T-cells. In mast cells, the activation of the IL4/IL13 locus is also regulated via epigenetic modulation (e.g. reviewed by ANSEL et al. [53]). However, epigenetic mechanisms in that region vary between mast cells and T-cells. While for T-cells some knowledge on the involvement of epigenetic modifications in cell commitment and function has been acquired, little is yet known for other cell types involved in asthma and allergy.

\section{ENVIRONMENTAL FACTORS POTENTIALLY AFFECTING EPIGENETIC MECHANISMS IN ASTHMA}

In addition to genetic susceptibility, environmental factors play an important role in the pathogenesis of asthma and allergy. Gene by environment interactions are thought to occur and to significantly influence disease development [54]. Epigenetic factors may mediate at least some of these environmental effects [55]. Thus, we systematically examined whether environmental factors known to have an impact on asthma and allergy have also been reported to induce epigenetic changes in experimental settings (table 1).

\section{Smoke exposure and epigenetics}

The single most consistent and significant environmental risk factor for the development of childhood onset asthma identified in numerous epidemiological studies is the exposure to tobacco smoke. Recent findings demonstrated that direct inhalation of cigarette smoke alters DNA methylation patterns in lung derived cells of mice shortly after exposure [63]. In humans, cancer-related studies $[67,68]$ reported gene promoter hypermethylation in sputum of cancer-free heavy smokers, suggesting the presence of epigenetic field defects prior to pathologically detectable cancers. Several studies associate in utero tobacco smoke exposure, smoking of the mother previous to pregnancy and even smoking by the grandmother to occurrence of asthma in the child or the grandchild, respectively [57, 69, 70]. Parental smoking affects the methylation of CpGs in the vicinity of numerous genes investigated in DNA collected from buccal cells of children [64]. Methylation was increased for AluYb8 and LINE1 repetitive elements and decreased for the promoter regions of AXL and PTPRO genes. Interestingly, genetically determined deficiency and genetic variation in detoxification genes of the glutathione $S$-transferase (GST) family seem to modify smoke-associated methylation effects [71]. This may be explained by the fact that GST

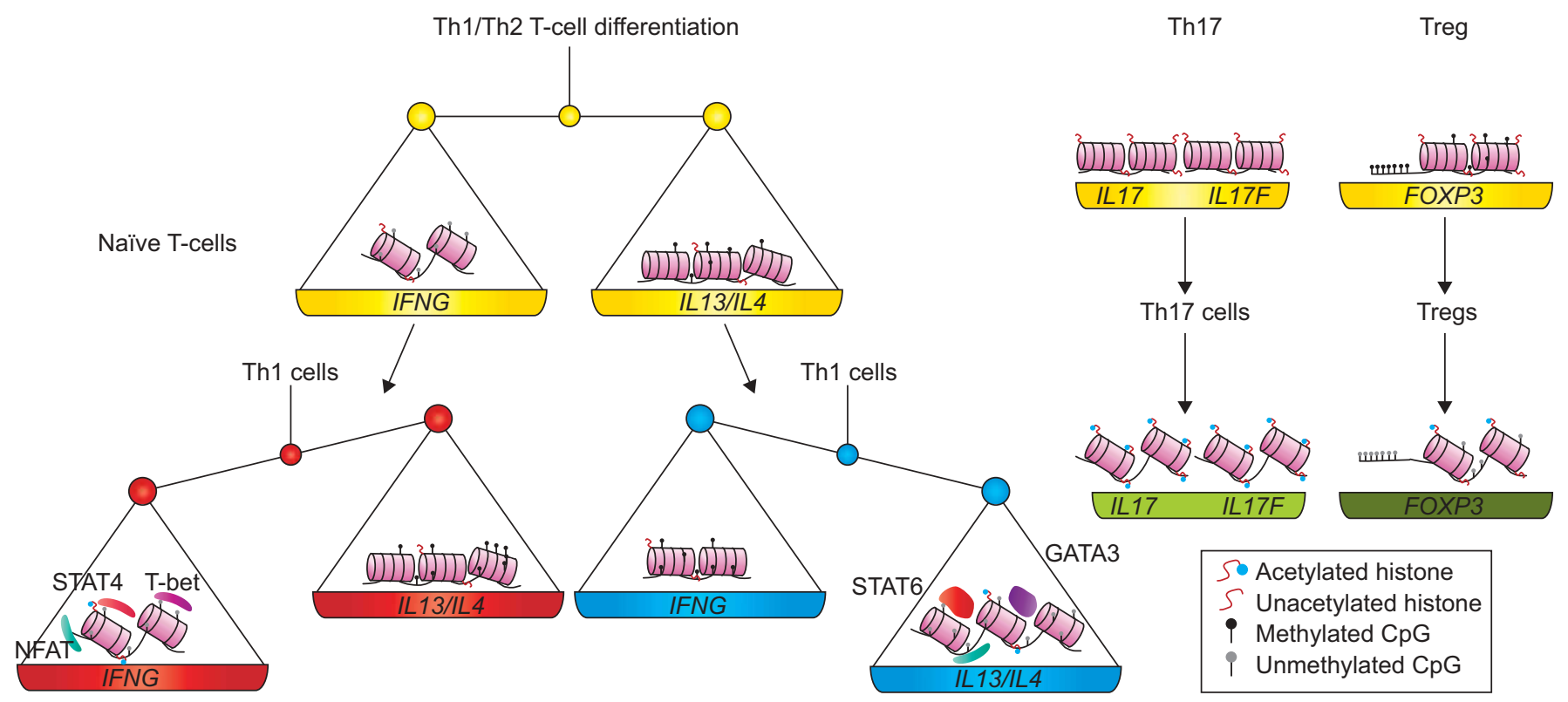

FIGURE 3. Different patterns of epigenetic mechanisms influence the differentiation and the maintenance of T-cells into T-helper type 1 (Th1), 2 (Th2) and 17 (Th17) cells or regulatory T-cells (Tregs), respectively. 
Fibroblast

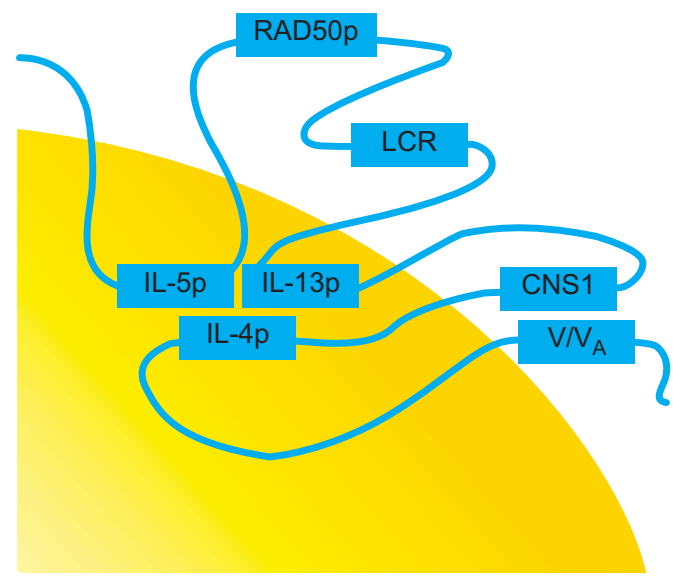

Core promoter interactions
Lymphocyte

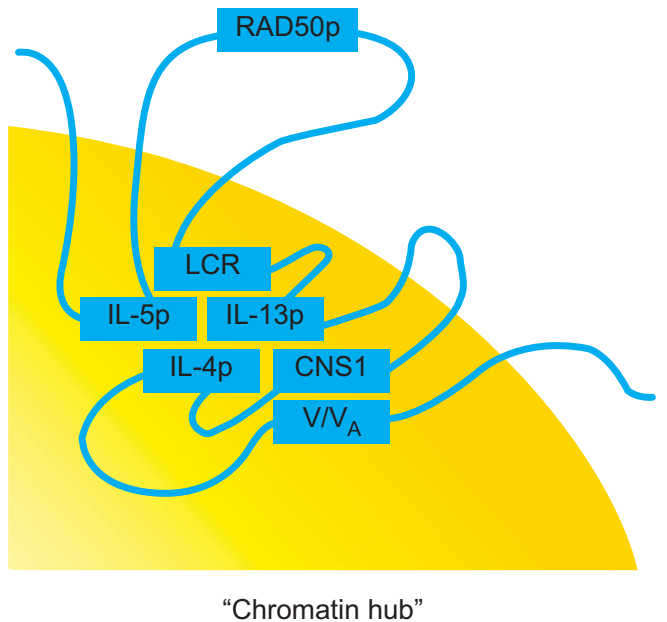

FIGURE 4. Complex three-dimensional structure of the interleukin (IL)13-IL4 locus. The cytokine gene promoters of IL5, IL13 and IL4 are suggested to interact with each other. This interaction is always present even if these cytokines are not transcribed, like in fibroblasts. For a transcription an interaction with additional intergenic regions in a "chromatin hub" is necessary as shown here in lymphocytes. Reproduced from [48] with permission from the publisher.

genes detoxify numerous cancerogenic compounds, which can facilitate methylation. Thus, genomic variations in GST genes could determine the level of epigenetically active substances acting on $\mathrm{CpGs}$ in disease-associated candidate genes. Furthermore, it has been shown that transcriptional activity of GST promoters depends on genetic variants and leads to differential DNA methylation susceptibility of the respective promoter, as recently demonstrated in a study of locally advanced breast cancer [72].

\section{Ozone and oxidative stress}

Exposure to elevated ozone levels is a well known trigger for exacerbation in asthma patients. The role of ozone in disease development is controversial. The hypothesis and the evidence that there may be a causal relationship between oxidative stress, DNA methylation and carcinogenesis was recently reviewed by FRANCO et al. [73]. A correlation between DNA methylation and oxidative stress has been proposed for Alzheimer disease [74]. Whether ozone-related epigenetic changes are involved in the development of asthma is still unknown.

\section{Traffic exposure}

An impact of traffic exposure on asthma development via epigenetic mechanisms was described by PERERA et al. [75]. They studied the influence of exposure to traffic-related air pollution in mothers on asthma development in their children. A correlation between a high exposure to polycyclic aromatic hydrocarbons (PAH) of the mothers and asthma was reported, which seemed to involve the DNA methylation of the ACSL3

TABLE 1 Environmental factors that have been reported to influence asthma and evidence for consequences at the level of epigenetic modifications induced by the same environmental factors

\begin{tabular}{|c|c|c|c|c|c|}
\hline Environmental factor & $\begin{array}{l}\text { Genes putatively } \\
\text { involved in gene- } \\
\text { environmental effects }\end{array}$ & $\begin{array}{l}\text { Epigenetic modifications } \\
\text { induced by the } \\
\text { environmental factor }\end{array}$ & $\begin{array}{c}\text { Target of epigenetic } \\
\text { effects }\end{array}$ & Tissue analysed/disease context & [Ref.] \\
\hline Passive smoking & $\operatorname{IL1R}[56]$ & DNA methylation & Global & Mouse lung tissue/lung cancer & [63] \\
\hline In utero smoking & GSTM1/GSTP1 [57] & DNA methylation & Global; AXL PTPRO & $\begin{array}{l}\text { Human buccal cells/effects of in utero } \\
\text { tobacco smoke }\end{array}$ & {$[64]$} \\
\hline Ozone/oxidative stress & TNF [58] & DNA methylation & Global & Murine melanocytes/cancer & [65] \\
\hline Farm exposure & $\begin{array}{l}\text { Innate immunity receptors } \\
\qquad[59,60]\end{array}$ & No data available & No data available & No data available & No data available \\
\hline Endotoxin & $C D 14[61,62]$ & Chromatin remodelling & TNF/IL-1 $\beta$ & $\begin{array}{c}\text { Human promomocytic cells (THP-1), blood } \\
\text { leukocytes/systemic inflammation }\end{array}$ & {$[66]$} \\
\hline
\end{tabular}

IL1R: interleukin-1 receptor; GSTM1: glutathione S-transferase Mu 1; GSTP1: glutathione S-transferase P1; TNF: tumour necrosis factor; IL-1 $\beta$ : interleukin-1 $\beta$; AXL: AXL receptor tyrosine kinase; PTPRO: protein tyrosine phosphatase, receptor type, $\mathrm{O}$. 
promoter. There, a higher PAH exposure leads to higher levels of methylation. A less active ACSL3 may diminish fatty acid utilization and beta-oxidation energy production, and may also have an impact on the phospholipid composition of cell membranes.

\section{Endotoxin and farm exposure}

Endotoxins are bacterial wall components, highly immunogenic and abundant in the environment. They are thought to be a good proxy for microbial exposure. In farm studies, protection against hay fever and atopic wheeze has been associated with high exposure levels of endotoxins [76]. Their role in asthma and allergy development is controversial and a causal relationship between endotoxin exposure and protection against allergy and asthma has not yet been established. Nonetheless, there are indications for gene by environment interactions, where differences in endotoxin levels affect associations between CD14 promoter polymorphisms and immunoglobulin (Ig)E mediated allergy [61, 62]. Endotoxin levels and farm exposure also influence the effect of toll-like receptor (TLR) polymorphisms on asthma and allergy in rural populations [59]. Furthermore, farm exposure (even prenatally) seems to influence the expression of innate immunityrelated receptors and molecules such as TLR2, TLR4 and CD14 $[60,76]$. Even though actual data are still missing, it would not be surprising if epigenetic mechanisms contribute substantially to these environmentally induced changes in gene expression. A single study investigating epigenetic effects of endotoxins on tumour necrosis factor (TNF) expression suggests that indeed endotoxins modulate TNF gene silencing by specific chromatin remodelling [66]. In addition it could be shown that histones $\mathrm{H} 3$ at the $I L-1 \beta$ promoter undergo demethylation after endotoxin stimulation in normal human leukocytes [77]. As these alterations were not observed in endotoxin-tolerant cells, this may indicate that epigenetic mechanisms might be involved in innate immunity response triggered by endotoxins.

\section{Diet}

An association between asthma-related phenotypes, DNA methylation and diet was proposed by HOLLINGSWORTH et al. [78]. The effect of a diet rich in methyl donors (folic acid) was studied in mice. The offspring of mice treated with folic acid displayed higher levels of airway hyperactivity, increased airway eosinophilic inflammation and higher levels of $\operatorname{IgE}$ production. The methyl-rich diet decreased transcriptional activity and mRNA expression of several genes, which was accompanied by DNA hypermethylation of the respective promoters. One of these differentially methylated genes was RUNX3, a gene linked to silencing of IL4 and activation of FOXP3 [79]. It could thus be speculated that changes of RUNX3 activity could influence allergic airway diseases.

The effects of a diet rich in folate on developing asthma was studied recently in an Australian prospective birth cohort. There, the intake of supplemental folic acid during the last months of pregnancy increased the risk of the child developing asthma [80]. Based on prior experimental data of folic acid in epigenetic studies, the authors speculated that the epidemiological effects observed may be epigenetic. However, no proof for this hypothesis was provided.
Folate is not the only dietary supplement suspected to display epigenetic effects. High calcium intake has been reported to influence associations of genetic variants with breast cancer in the gene coding for the vitamin D receptor (VDR) [81]. In choriocarcinoma cells the activity of $V D R$ was found to be probably epigenetically controlled, as silenced $V D R$ could be activated through the inhibition of either DNA methylation or histone deacetylation [82]. These observations suggest that $V D R$ is involved in epigenetic mechanisms, an interesting observation as genetic polymorphisms in $V D R$ have been associated with asthma and airway hyperresponsiveness [83]. Reduced levels of vitamin $\mathrm{D}$ have been shown to be associated with elevated markers of allergy and asthma severity [84].

However, not only the intake of dietary supplements but also malnutrition or undernourishment influences epigenetic regulation and subsequent development of disease. In a crosssectional study of African-Americans high fat consumption and diabetes was associated with a hypermethylated $R A R \beta 2$ promoter [85]. In undernourished rats, a relationship between the amount of protein in the nutrition and the methylation of the $A T 1 b$ angiotensin II receptor gene in their offspring [86] was observed. The progeny of the study group fed with substantially decreased amounts of protein showed a demethylation of the $A T 1 b$ promoter. Demethylation of the promoter led to elevated expression of $A T 1 b$, which was suggested to be causal for the hypertension observed in these rats.

In humans, famine in previous generations may affect methylation in offspring as it was suggested in a study investigating potential DNA methylation alterations in Dutch individuals whose parents were exposed to a period of severe famine at the end of World War II. There, changes in methylation of IL10, an important regulator of inflammation potentially involved in asthma and allergy development, were observed [87]. Children concerned by the famine showed, in contrast to their unexposed siblings, a hypermethylated IL10 promoter.

\section{PUTATIVE TARGET GENES FOR EPIGENETIC MODIFICATION IN ASTHMA}

After analysing published evidence for epigenetic effects on asthma induced by environmental factors, we also investigated putative asthma candidate genes for their potential to be regulated by epigenetic mechanisms. Three strategies were applied to systematically identify: 1) genes harbouring single nucleotide polymorhisms that showed associations with asthma in at least five independent studies based on extensive in silico data mining; 2) genes that had been suggested by a recent comprehensive review of the field to be one of 10 important asthma candidate genes [88]; and 3) asthma genes recently identified by genome-wide association studies (GWAS) [89-92], even though only very limited data are yet available for GWAS genes.

Asthma candidate genes selected according to these three aforementioned criteria for which evidence for epigenetic regulation exists are summarised in table 2. Putative asthma candidate genes for which no published evidence for epigenetic regulation was found are $A D R B 2, C D 14, C H I 3 L 1$, CHRNA2, DENND1B, GSDMA, HLA-DRB1, IL1RL1, IL33, $M Y B, N P S R 1$, PSMD3, TLE4 and WDR36. 


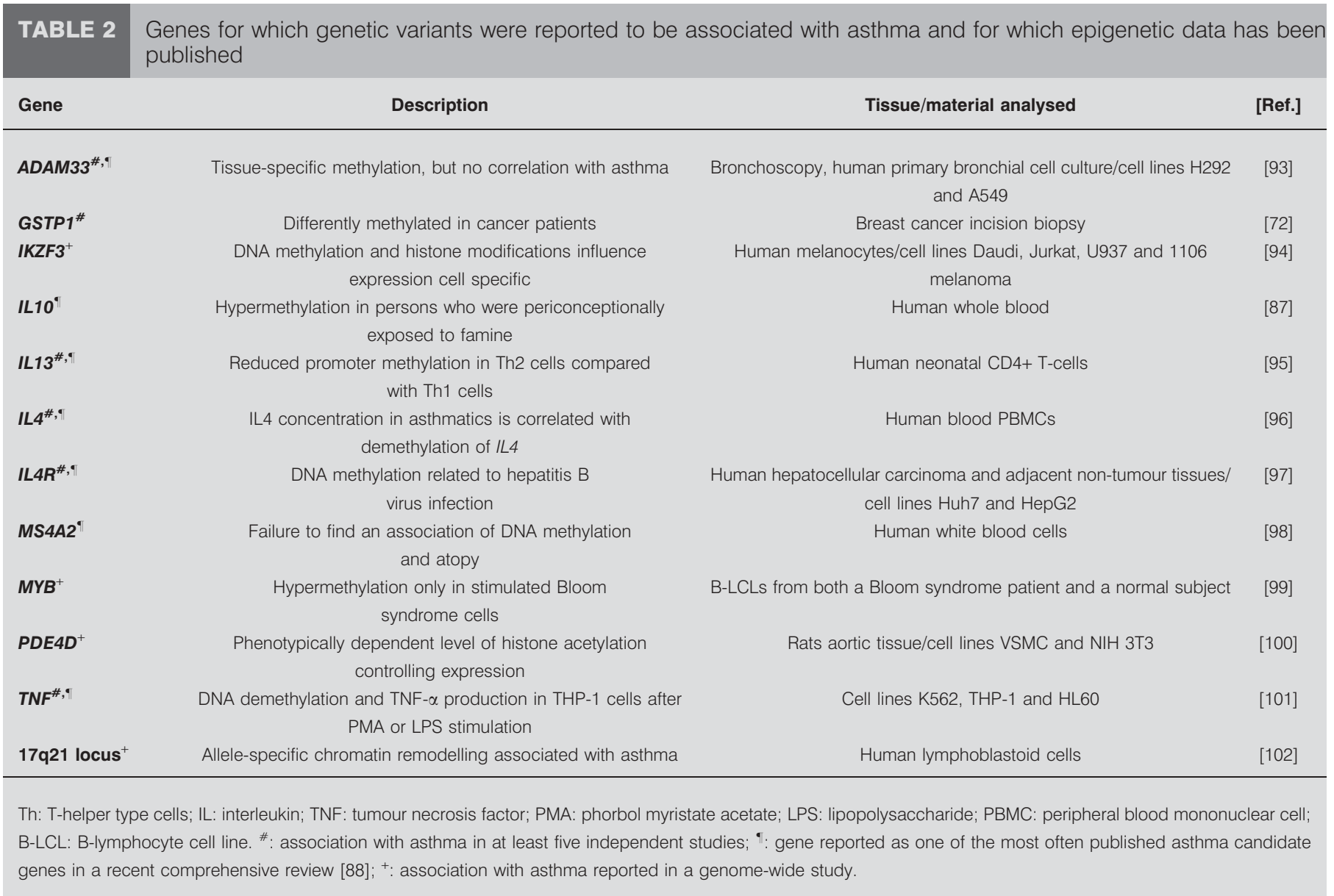

The epigenetic regulation of the IL4/IL13 locus on chromosome 5 q31 has been extensively studied. As these genes have been studied in the context of T-cell regulation and differentiation, these studies have already been discussed in a previous section of this review. In addition, KWON et al. [96] claimed that CpG methylation in the IL4 and IFNG promoters differed in asthmatics and non-asthmatics after stimulation with phytohaemagglutinin. However, their observation was limited to three cases and three controls only. Obviously, additional studies for validation are required before conclusions can be drawn on whether methylation patterns in this locus differ between asthmatics and nonasthmatics.

For $A D A M 33$ it could be shown that the promoter region of the gene is differentially methylated in epithelial cells and fibroblasts [93]. However, these differences were independent of asthma status in the analysed samples. Methylation patterns of CpGs related to $M S 4 A 2$, coding for the beta-chain of the $\operatorname{IgE}$ high-affinity receptor, were recently investigated in people with and without atopy [98]. Variation in methylation at this locus in peripheral blood lymphocytes was not associated with age, sex, daily steroid use or atopic status, and there were no differences in methylation between mothers and fathers of atopic cases. Both these studies stress the importance of selecting specific cell subsets for epigenetic analysis that are relevant for disease development. As it is not yet clear which cells are crucial for asthma and atopy development (epithelial cells versus immune cells; cells in circulation versus those at the locus of inflammation), epigenetic analyses in asthma and allergy are severely limited.

For a region on chromosome 17q21 strongly associated with childhood asthma in the first GWAS for asthma (and numerous subsequent replication studies) [91], some evidence for epigenetic regulation exists. The locus contains ORMDL3, GSDMB and $Z P B P$ as well as other genes. In a recent study, genetic variants associated with asthma affected chromatin remodelling of a regulatory element controlling accessibility to the entire locus [102]. Furthermore, the expression of IKZF3, another putative candidate gene in the $17 \mathrm{q} 21$ region coding for a zinc finger with potential immunogenic effects, may also be influenced by epigenetic mechanisms. Evidence derives from tumour cell studies, in which IKZF3 displays differential methylation in cell lines and its expression is silenced by methylation of the $\mathrm{CpG}$ island associated with the transcription start site [94].

For PDE $4 D$, a further asthma candidate gene suggested by a GWAS [90], epigenetic data had been acquired previously to the GWAS. PDE $4 D$ encodes several isoforms and the expression of PDE4D1 and PDE4D2 is regulated by an intronic $P D E 4 D$ promoter. At least in vascular smooth muscle cells, experiments based on chromatin immunoprecipitation showed phenotype-specific gene expression influenced by histone acetylation [100]. The promoter was acetylated only in vascular smooth muscle cells derived from damaged blood vessels, whereas in cells derived from healthy arteries, histones were 
not acetylated. No data exists on immune cells or lung specific effects.

\section{ALTERATIONS OF MIRNA EXPRESSION IN ASTHMA}

miRNAs are small single-stranded noncoding RNAs that are highly conserved across species and function as endogenous regulators of numerous target genes [103]. Hundreds of human miRNAs localised in the introns of protein-coding genes or in the noncoding regions of the genome have been identified in the human genome. They are expressed in a tissue-specific manner and play important roles in cell proliferation, apoptosis, and differentiation during mammalian development. miRNAs are able to negatively regulate expression through degradation of mRNA transcripts or inhibition of protein translation. It has been estimated that up to $30 \%$ of all genes might be regulated through miRNAs [104]. miRNAs play also an important role in the regulation of the immune system and the differentiation of the different lineages of the haematopoietic system [105]. Aberrant expression of miRNAs may contribute to the development and progression of many human diseases, including asthma. For example, miR-223 might be involved in granulocyte production and the inflammatory response, as a mouse model mutated for miR-223 displayed neutrophilic inflammatory lung pathology and increased tissue destruction after endotoxin challenge [106]. In another mouse model of house dust mite-induced allergic asthma, the asthmatic inflammation was found to be associated with a characteristic miRNA expression profile, in particular upregulation of miR-126 which suppressed the effector function of lung Th2 cells [107]. Whether the observed changes in the mouse models are relevant to human asthma has so far not been investigated. A study analysing 227 miRNAs in airway biopsies from normal and mild asthmatic patients revealed cell type-specific miRNA profiles but no miRNAs associated to asthma [108].

\section{CRITICAL ASSESSMENT AND OUTLOOK}

Epigenetic studies in asthma are, as in many other complex diseases, at a very early stage. It would be surprising if epigenetic regulation would not be involved in the development and the natural course of a disease like asthma which is driven by environmental as well as genetic susceptibility factors. However existing epigenetic data is sparse (so far). Most of those studies were focused on mechanisms related to asthma (like T-cell lineage commitment) rather than on disease development itself. Reasons for that are manifold.

Asthma is a syndrome rather than a homogenous disease, involving numerous mechanisms acting in concert with each other, in parallel to each other, or against each other. Many different clinical phenotypes are summarised under the umbrella of an asthma diagnosis. While these asthma phenotypes share common clinical features, their molecular pathogenesis may differ greatly. This is of lesser concern when strong effects are studied in very large epidemiological or genetic studies on thousands of individuals. There, strong effects from small subpopulations may become significant enough to be identified. In epigenetics as it is studied today, numerous conditions have to be optimised a priori to detect epigenetic effects. In genetic studies, it does not matter from which cell type or cell state genomic DNA derives. The genetic code is universal and uniform in almost all cells. Epigenetic regulation has a different function. It allows for flexibility in the interpretation of DNA based information in specific cells and serves as a "flash memory" by transforming environmental effects into epigenetic patterns. This is the very reason why studying epigenetics is of interest in complex diseases. At the same time it causes serious challenges to epigenetic studies.

Choosing the right tissue in which to study epigenetics in complex diseases is a difficult task. Because cell types differ in their epigenetic patterns, an undefined mixture of cells is unarguably difficult to analyse. Thus, whole blood samples, while easy to obtain in large numbers in epidemiological settings, have to be reviewed critically in studies of an airway disease such as asthma. Lung tissue or well-defined cell types closely correlated to the pathogenesis of asthma would be ideal. However, so far it remains unclear which cells, cell types or tissues are involved in the onset of asthma.

Therefore, different (parallel) strategies to study asthma epigenetics are conceivable for the future. One possibility would be to vigorously dissect asthma phenotypes and to investigate epigenetic patterns in all variable sources of tissue in these highly selected individuals. While scientifically satisfying the drawback of this approach is the enormous efforts and costs needed to achieve sample collections of a size necessary for epigenetic studies in asthma subpopulations. Also, it may prove impossible to acquire relevant numbers of lung tissue samples in children. An alternative study design is to investigate effects of strong environmental factors identified to influence asthma development, such as microbial, allergen or smoke exposure, on epigenetics. With this approach, sample collection of considerable size could be established rather easily. These would be sufficient to study epigenetics on a broad basis in numbers large enough to level out false-positive associations and to identify subgroup effects. How feasible whole blood samples would be in such approaches has to be seen. The question remaining for both designs is what epigenetic effects to study, and in which genomic regions.

Also, the complexity of epigenetics is just starting to unravel. Methylation is not the only mechanism involved in epigenetic regulation. However, it is the one best understood and most accessible to high throughput analyses. Focusing on analysing DNA methylation patterns is a reasonable first approach. However, it may turn out not to be the epigenetic modification most important in asthma related mechanisms. Pyrosequencing bisulphite treated DNA is state of the art today, capable of handling relatively large sample numbers, but also this technique is limited to sequences of $\sim 300$ base pairs in length [109]. Thus, pyrosequencing is more feasible for validation than for scanning the epigenome for novel associations.

At this point, epigenetic studies in complex diseases rely heavily on experience gathered in the cancer field, where epigenetic mechanisms have already been investigated for a long time. A large number of genome-wide methods for DNA methylation analysis have been developed and due to the advent of novel sequencing technologies they become ever more powerful [110]. CpG islands and transcription start sites may be important in cancer but could prove to be less important sites of epigenetic regulation in complex diseases [111]. Thus, 
many of the currently available techniques might not yet have the required quantitative and spatial resolution to detect the subtle changes that might be implicated in complex diseases such as asthma. To our knowledge, no genome-wide DNA methylation study has so far been performed and published in asthma. Genome-wide bisulphite sequencing would constitute the ideal method for the unbiased detection of alterations in DNA methylation patterns [112], but the increased genome size (the genome size doubles as the two DNA strands are no longer complementary) in combination with the reduced sequence complexity and the required sequencing depth to achieve sufficient quantitative resolution makes it currently a daunting and cost-prohibitive endeavour for the analysis of several epigenomes. The rapid technological evolution, the expected decline in sequencing costs and the potential for direct read-out of methylated cytosines by some technologies under development (e.g. nanopores) will probably make these studies feasible in the next few years. Thus, it is important for the field to move on and to establish novel techniques and approaches to study epigenetics in complex diseases specifically. It will remain a challenge for the next few years.

\section{STATEMENT OF INTEREST}

A statement of interest for M. Kabesch can be found at www.erj. ersjournals.com $/ \mathrm{misc} /$ statements.dtl

\section{ACKNOWLEDGEMENTS}

This systematic review was supported by funding from the European Union, EU FP7 KBBE-2007-2-2-06 (EFRAIM). S. Michel is also supported by a PINA fellowship. Chemical structures were drawn with Jmol (an open-source Java viewer for chemical structures in 3D; www.jmol.org).

\section{REFERENCES}

1 Tost J. Epigenetics. Norwich, Horizon Scientific Press, 2008.

2 Kouzarides T. Chromatin modifications and their function. Cell 2007; 128: 693-705.

3 Nightingale KP, O'Neill LP, Turner BM. Histone modifications: signalling receptors and potential elements of a heritable epigenetic code. Curr Opin Genet Dev 2006; 16: 125-136.

4 Bird A. DNA methylation patterns and epigenetic memory. Genes Dev 2002; 16: 6-21.

5 Antequera F. Structure, function and evolution of $\mathrm{CpG}$ island promoters. Cell Mol Life Sci 2003; 60: 1647-1658.

6 Friso S, Choi SW, Girelli D, et al. A common mutation in the 5,10methylenetetrahydrofolate reductase gene affects genomic DNA methylation through an interaction with folate status. Proc Natl Acad Sci 2002; 99: 5606-5611.

7 Klose RJ, Bird AP. Genomic DNA methylation: the mark and its mediators. Trends Biochem Sci 2006; 31: 89-97.

8 Cheng AS, Culhane AC, Chan MW, et al. Epithelial progeny of estrogen-exposed breast progenitor cells display a cancer-like methylome. Cancer Res 2008; 68: 1786-1796.

9 Jiricny J, Menigatti M. DNA cytosine demethylation: are we getting close? Cell 2008; 135: 1167-1169.

10 Ooi SK, Bestor TH. The colorful history of active DNA demethylation. Cell 2008; 133: 1145-1148.

11 Geiman TM, Robertson KD. Chromatin remodeling, histone modifications, and DNA methylation-how does it all fit together? J Cell Biochem 2002; 87: 117-125.

12 Sasai N, Defossez PA. Many paths to one goal? The proteins that recognize methylated DNA in eukaryotes. Int J Dev Biol 2009; 53: 323-334.
13 Guibert S, Forné T, Weber M. Dynamic regulation of DNA methylation during mammalian development. Epigenomics 2009; 1: 81-98.

14 Reik W, Dean W, Walter J. Epigenetic reprogramming in mammalian development. Science 2001; 293: 1089-1093.

15 Reik W, Walter J. Genomic imprinting: parental influence on the genome. Nat Rev Genet 2001; 2: 21-32.

16 Holmes R, Soloway PD. Regulation of imprinted DNA methylation. Cytogenet Genome Res 2006; 113: 122-129.

17 Lewis A, Reik W. How imprinting centres work. Cytogenet Genome Res 2006; 113: 81-89.

18 Yoder JA, Walsh CP, Bestor TH. Cytosine methylation and the ecology of intragenomic parasites. Trends Genet 1997; 13: 335-340.

19 Chow J, Heard E. X inactivation and the complexities of silencing a sex chromosome. Curr Opin Cell Biol 2009; 21: 359-366.

20 Fraga MF, Ballestar E, Paz MF, et al. Epigenetic differences arise during the lifetime of monozygotic twins. Proc Natl Acad Sci 2005; 102: 10604-10609.

21 Tufarelli C, Stanley JA, Garrick D, et al. Transcription of antisense RNA leading to gene silencing and methylation as a novel cause of human genetic disease. Nat Genet 2003; 34: 157-165.

22 Jones PA, Baylin SB. The epigenomics of cancer. Cell 2007; 128: 683-692.

23 Laird PW. Early detection: the power and the promise of DNA methylation markers. Nat Rev Cancer 2003; 3: 253-266.

24 Tost J. Analysis of DNA methylation patterns for the early diagnosis, classification and therapy of human cancers. In: Kobayashi TB, ed. DNA Methylation Research Trends. Hauppauge, Nova Science Publishers 2007; pp. 87-133.

25 Yoo CB, Jones PA. Epigenetic therapy of cancer: past, present and future. Nat Rev Drug Discov 2006; 5: 37-50.

26 van Vliet J, Oates NA, Whitelaw E. Epigenetic mechanisms in the context of complex diseases. Cell Mol Life Sci 2007; 64: 1531-1538.

27 Bateson P, Barker D, Clutton-Brock T, et al. Developmental plasticity and human health. Nature 2004; 430: 419-421.

28 Stoger R. The thrifty epigenotype: an acquired and heritable predisposition for obesity and diabetes? Bioessays 2008; 30: 156-166.

29 Tang WY, Ho SM. Epigenetic reprogramming and imprinting in origins of disease. Rev Endocr Metab Disord 2007; 8: 173-182.

30 Gluckman PD, Hanson MA, Buklijas T, et al. Epigenetic mechanisms that underpin metabolic and cardiovascular diseases. Nat Rev Endocrinol 2009; 5: 401-408.

31 Morgan DK, Whitelaw E. The case for transgenerational epigenetic inheritance in humans. Mamm Genome 2008; 19: 394-397.

32 Zaina S, Lindholm MW, Lund G. Nutrition and aberrant DNA methylation patterns in atherosclerosis: more than just hyperhomocysteinemia? J Nutr 2005; 135: 5-8.

33 Lund G, Andersson L, Lauria M, et al. DNA methylation polymorphisms precede any histological sign of atherosclerosis in mice lacking apolipoprotein E. J Biol Chem 2004; 279: 29147-29154.

34 Karouzakis E, Gay RE, Gay S, et al. Epigenetic control in rheumatoid arthritis synovial fibroblasts. Nat Rev Rheumatol 2009; 5: 266-272.

35 Richardson B, Scheinbart L, Strahler J, et al. Evidence for impaired T cell DNA methylation in systemic lupus erythematosus and rheumatoid arthritis. Arthritis Rheum 1990; 33: 1665-1673.

36 Gorelik G, Richardson B. Aberrant T cell ERK pathway signaling and chromatin structure in lupus. Autoimmun Rev 2009; 8: 196-198.

37 Zhou Y, Lu Q. DNA methylation in T cells from idiopathic lupus and drug-induced lupus patients. Autoimmun Rev 2008; 7: 376-383.

38 Ito K, Caramori G, Lim S, et al. Expression and activity of histone deacetylases in human asthmatic airways. Am J Respir Crit Care Med 2002; 166: 392-396. 
39 Cosio BG, Mann B, Ito K, et al. Histone acetylase and deacetylase activity in alveolar macrophages and blood mononocytes in asthma. Am J Respir Crit Care Med 2004; 170: 141-147.

40 Imhof A, Wolffe AP. Transcription: gene control by targeted histone acetylation. Curr Biol 1998; 8: R422-R424.

41 Ito $\mathrm{K}$, Ito $\mathrm{M}$, Elliott WM, et al. Decreased histone deacetylase activity in chronic obstructive pulmonary disease. $N$ Engl J Med 2005; 352: 1967-1976.

42 Maggi E. The TH1/TH2 paradigm in allergy. Immunotechnology 1998; 3: 233-244.

43 Larche M. Regulatory T cells in allergy and asthma. Chest 2007; 132: 1007-1014.

44 Lee DU, Agarwal S, Rao A. Th2 lineage commitment and efficient IL-4 production involves extended demethylation of the IL-4 gene. Immunity 2002; 16: 649-660.

45 Avni O, Lee D, Macian F, et al. TH cell differentiation is accompanied by dynamic changes in histone acetylation of cytokine genes. Nat Immunol 2002; 3: 643-651.

46 Chen GY, Osada H, Santamaria-Babi LF, et al. Interaction of GATA-3/T-bet transcription factors regulates expression of sialyl Lewis $\mathrm{X}$ homing receptors on Th1/Th2 lymphocytes. Proc Natl Acad Sci 2006; 103: 16894-16899.

47 Jones $B$, Chen J. Inhibition of IFN-gamma transcription by sitespecific methylation during $\mathrm{T}$ helper cell development. EMBO J 2006; 25: 2443-2452.

48 Ansel KM, Djuretic I, Tanasa B, et al. Regulation of Th2 differentiation and Il4 locus accessibility. Annu Rev Immunol 2006; 24: 607-656.

49 Lal G, Zhang N, van der Touw W, et al. Epigenetic regulation of Foxp3 expression in regulatory $\mathrm{T}$ cells by DNA methylation. J Immunol 2009; 182: 259-273.

50 Floess S, Freyer J, Siewert C, et al. Epigenetic control of the foxp3 locus in regulatory T cells. PLoS biology 2007; 5: e38.

51 Tao R, de Zoeten EF, Ozkaynak E, et al. Deacetylase inhibition promotes the generation and function of regulatory T cells. Nat Med 2007; 13: 1299-1307.

52 Akimzhanov AM, Yang XO, Dong C. Chromatin remodeling of interleukin-17 (IL-17)-IL-17F cytokine gene locus during inflammatory helper $\mathrm{T}$ cell differentiation. I Biol Chem 2007; 282: 5969-5972.

53 Ansel KM, Lee DU, Rao A. An epigenetic view of helper T cell differentiation. Nat Immunol 2003; 4: 616-623.

54 Cookson $\mathrm{W}$. The alliance of genes and environment in asthma and allergy. Nature 1999; 402: Suppl. 6760, B5-B11.

55 Miller RL, Ho SM. Environmental epigenetics and asthma: current concepts and call for studies. Am J Respir Crit Care Med 2008; 177: 567-573.

56 Ramadas RA, Sadeghnejad A, Karmaus W. Interleukin-1R antagonist gene and pre-natal smoke exposure are associated with childhood asthma. Eur Respir J 2007; 29: 502-508.

57 Li YF, Gauderman WJ, Conti DV, et al. Glutathione S-transferase P1, maternal smoking, and asthma in children: a haplotypebased analysis. Environ Health Perspect 2008; 116: 409-415.

58 Li YF, Gauderman WJ, Avol E, et al. Associations of tumor necrosis factor G-308A with childhood asthma and wheezing. Am J Respir Crit Care Med 2006; 173: 970-976.

59 Eder W, Klimecki W, Yu L, et al. Toll-like receptor 2 as a major gene for asthma in children of European farmers. J Allergy Clin Immunol 2004; 113: 482-488.

60 Ege MJ, Bieli C, Frei R, et al. Prenatal farm exposure is related to the expression of receptors of the innate immunity and to atopic sensitization in school-age children. J Allergy Clin Immunol 2006; 117: 817-823.

61 Simpson A, John SL, Jury F, et al. Endotoxin exposure, CD14, and allergic disease: an interaction between genes and the environment. Am J Respir Crit Care Med 2006; 174: 386-392.
62 Zambelli-Weiner A, Ehrlich E, Stockton ML, et al. Evaluation of the CD14/-260 polymorphism and house dust endotoxin exposure in the Barbados Asthma Genetics Study. I Allergy Clin Immunol 2005; 115: 1203-1209.

63 Phillips JM, Goodman JI. Inhalation of cigarette smoke induces regions of altered DNA methylation (RAMs) in SENCAR mouse lung. Toxicology 2009; 260: 7-15.

64 Breton CV, Byun HM, Wenten M, et al. Prenatal tobacco smoke exposure affects global and gene-specific DNA methylation. Am J Respir Crit Care Med 2009; 180: 462-467.

65 Campos AC, Molognoni F, Melo FH, et al. Oxidative stress modulates DNA methylation during melanocyte anchorage blockade associated with malignant transformation. Neoplasia 2007; 9: 1111-1121.

66 El Gazzar M, Yoza BK, Chen X, et al. Chromatin-specific remodeling by HMGB1 and linker histone $\mathrm{H} 1$ silences proinflammatory genes during endotoxin tolerance. Mol Cell Biol 2009; 29: 1959-1971.

67 Belinsky SA, Liechty KC, Gentry FD, et al. Promoter hypermethylation of multiple genes in sputum precedes lung cancer incidence in a high-risk cohort. Cancer Res 2006; 66: 3338-3344.

68 Baryshnikova E, Destro A, Infante MV, et al. Molecular alterations in spontaneous sputum of cancer-free heavy smokers: results from a large screening program. Clin Cancer Res 2008; 14 1913-1919.

69 Xepapadaki P, Manios Y, Liarigkovinos T, et al. Association of passive exposure of pregnant women to environmental tobacco smoke with asthma symptoms in children. Pediatr Allergy Immunol 2009; 20: 423-429.

70 Li YF, Langholz B, Salam MT, et al. Maternal and grandmaternal smoking patterns are associated with early childhood asthma. Chest 2005; 127: 1232-1241.

71 Lin $\mathrm{IH}, \mathrm{Chao} \mathrm{MR}, \mathrm{Hu} \mathrm{CW}$, et al. Modification of urinary N7methylguanine excretion in smokers by glutathione-S-transferase M1 polymorphism. Toxicology 2009; 260: 1-6.

72 Ronneberg JA, Tost J, Solvang HK, et al. GSTP1 promoter haplotypes affect DNA methylation levels and promoter activity in breast carcinomas. Cancer Res 2008; 68: 5562-5571.

73 Franco R, Schoneveld O, Georgakilas AG, et al. Oxidative stress, DNA methylation and carcinogenesis. Cancer Lett 2008; 266: 6-11.

74 Zawia NH, Lahiri DK, Cardozo-Pelaez F. Epigenetics, oxidative stress, and Alzheimer disease. Free Radic Biol Med 2009; 46: 1241-1249.

75 Perera F, Tang WY, Herbstman J, et al. Relation of DNA methylation of $5^{\prime}-\mathrm{CpG}$ island of ACSL3 to transplacental exposure to airborne polycyclic aromatic hydrocarbons and childhood asthma. PLoS One 2009; 4: e4488.

76 Braun-Fahrlander C, Riedler J, Herz U, et al. Environmental exposure to endotoxin and its relation to asthma in school-age children. N Engl J Med 2002; 347: 869-877.

77 Chan C, Li L, McCall CE, et al. Endotoxin tolerance disrupts chromatin remodeling and NF-kappaB transactivation at the IL1beta promoter. J Immunol 2005; 175: 461-468.

78 Hollingsworth JW, Maruoka S, Boon K, et al. In utero supplementation with methyl donors enhances allergic airway disease in mice. J Clin Invest 2008; 118: 3462-3469.

79 Bruno L, Mazzarella L, Hoogenkamp M, et al. Runx proteins regulate Foxp3 expression. J Exp Med 2009; 206: 2329-2337.

80 Whitrow MJ, Moore VM, Rumbold AR, et al. Effect of supplemental folic acid in pregnancy on childhood asthma: a prospective birth cohort study. Am J Epidemiol 2009; 170: 1486-1493.

81 McCullough ML, Stevens VL, Diver WR, et al. Vitamin D pathway gene polymorphisms, diet, and risk of postmenopausal breast cancer: a nested case-control study. Breast Cancer Res 2007; 9: R9. 
82 Pospechova K, Rozehnal V, Stejskalova L, et al. Expression and activity of vitamin $\mathrm{D}$ receptor in the human placenta and in choriocarcinoma BeWo and JEG-3 cell lines. Mol Cell Endocrinol 2009; 299: 178-187.

83 Daley D, Lemire M, Akhabir L, et al. Analyses of associations with asthma in four asthma population samples from Canada and Australia. Hum Genet 2009; 125: 445-459.

84 Brehm JM, Celedon JC, Soto-Quiros ME, et al. Serum vitamin D levels and markers of severity of childhood asthma in Costa Rica. Am J Respir Crit Care Med 2009; 179: 765-771.

85 Brait M, Ford JG, Papaiahgari S, et al. Association between lifestyle factors and $\mathrm{CpG}$ island methylation in a cancer-free population. Cancer Epidemiol Biomarkers Prev 2009; 18: 2984-2991.

86 Bogdarina I, Welham S, King PJ, et al. Epigenetic modification of the renin-angiotensin system in the fetal programming of hypertension. Circ Res 2007; 100: 520-526.

87 Tobi EW, Lumey LH, Talens RP, et al. DNA methylation differences after exposure to prenatal famine are common and timing- and sex-specific. Hum Mol Genet 2009; 18: 4046-4053.

88 Vercelli D. Discovering susceptibility genes for asthma and allergy. Nat Rev Immunol 2008; 8: 169-182.

89 Hancock DB, Romieu I, Shi M, et al. Genome-wide association study implicates chromosome $9 \mathrm{q} 21.31$ as a susceptibility locus for asthma in Mexican children. PLoS Genet 2009; 5: e1000623.

90 Himes BE, Hunninghake GM, Baurley JW, et al. Genome-wide association analysis identifies PDE4D as an asthma-susceptibility gene. Am J Hum Genet 2009; 84: 581-593.

91 Moffatt MF, Kabesch M, Liang L, et al. Genetic variants regulating ORMDL3 expression contribute to the risk of childhood asthma. Nature 2007; 448: 470-473.

92 Ober C, Tan Z, Sun Y, et al. Effect of variation in CHI3L1 on serum YKL-40 level, risk of asthma, and lung function. $N$ Engl J Med 2008; 358: 1682-1691.

93 Yang Y, Haitchi HM, Cakebread J, et al. Epigenetic mechanisms silence a disintegrin and metalloprotease 33 expression in bronchial epithelial cells. J Allergy Clin Immunol 2008;121, 13931399: 1399.e1-1399.e14.

94 Duhamel M, Navarro P, Cario-Andre M, et al. Differential epigenetic regulation of Aiolos expression in human tumoral cell lines and primary cells. FEBS Lett 2008; 582: 457-467.

95 Webster RB, Rodriguez Y, Klimecki WT, et al. The human IL-13 locus in neonatal CD4+ $\mathrm{T}$ cells is refractory to the acquisition of a repressive chromatin architecture. J Biol Chem 2007; 282: 700-709.

96 Kwon NH, Kim JS, Lee JY, et al. DNA methylation and the expression of IL-4 and IFN-gamma promoter genes in patients with bronchial asthma. J Clin Immunol 2008; 28: 139-146.

97 Zheng DL, Zhang L, Cheng N, et al. Epigenetic modification induced by hepatitis $\mathrm{B}$ virus $\mathrm{X}$ protein via interaction with de novo DNA methyltransferase DNMT3A. J Hepatol 2009; 50: 377-387.

98 Ferreira MA, Oates NA, van Vliet J, et al. Characterization of the methylation patterns of MS4A2 in atopic cases and controls. Allergy 2009; 65: 333-337.

99 Bhalla A, Sachdeva G, Bamezai R. T-cell receptor-gamma rearrangement and c-myb methylation in MNNG-exposed Bloom syndrome B-lymphoblastoid cells. Cancer Lett 1998; 126: $1-6$.

100 Tilley DG, Maurice DH. Vascular smooth muscle cell phenotypedependent phosphodiesterase 4D short form expression: role of differential histone acetylation on cAMP-regulated function. Mol Pharmacol 2005; 68: 596-605.

101 Sullivan KE, Reddy $\mathrm{AB}$, Dietzmann $\mathrm{K}$, et al. Epigenetic regulation of tumor necrosis factor alpha. Mol Cell Biol 2007; 27: 5147-5160.

102 Verlaan DJ, Berlivet S, Hunninghake GM, et al. Allele-specific chromatin remodeling in the ZPBP2/GSDMB/ORMDL3 locus associated with the risk of asthma and autoimmune disease. Am J Hum Genet 2009; 85: 377-393.

103 Bartel DP. MicroRNAs: genomics, biogenesis, mechanism, and function. Cell 2004; 116: 281-297.

104 Lewis BP, Burge CB, Bartel DP. Conserved seed pairing, often flanked by adenosines, indicates that thousands of human genes are microRNA targets. Cell 2005; 120: 15-20.

105 O'Connell RM, Rao DS, Chaudhuri AA, et al. Physiological and pathological roles for microRNAs in the immune system. Nat Rev Immunol, 10: 111-122.

106 Johnnidis JB, Harris MH, Wheeler RT, et al. Regulation of progenitor cell proliferation and granulocyte function by microRNA-223. Nature 2008; 451: 1125-1129.

107 Mattes J, Collison A, Plank M, et al. Antagonism of microRNA126 suppresses the effector function of $\mathrm{TH} 2$ cells and the development of allergic airways disease. Proc Natl Acad Sci 2009; 106: 18704-18709.

108 Williams AE, Larner-Svensson H, Perry MM, et al. MicroRNA expression profiling in mild asthmatic human airways and effect of corticosteroid therapy. PLoS One 2009; 4: e5889.

109 Tost J, Gut IG. DNA methylation analysis by pyrosequencing. Nat Protoc 2007; 2: 2265-2275.

110 Laird PW. Principles and challenges of genome-wide DNA methylation analysis. Nat Rev Genet, 11: 191-203.

111 Eckhardt F, Lewin J, Cortese R, et al. DNA methylation profiling of human chromosomes 6, 20 and 22. Nat Genet 2006; 38: 1378-1385.

112 Lister R, Pelizzola $M$, Dowen RH, et al. Human DNA methylomes at base resolution show widespread epigenomic differences. Nature 2009; 462: 315-322. 